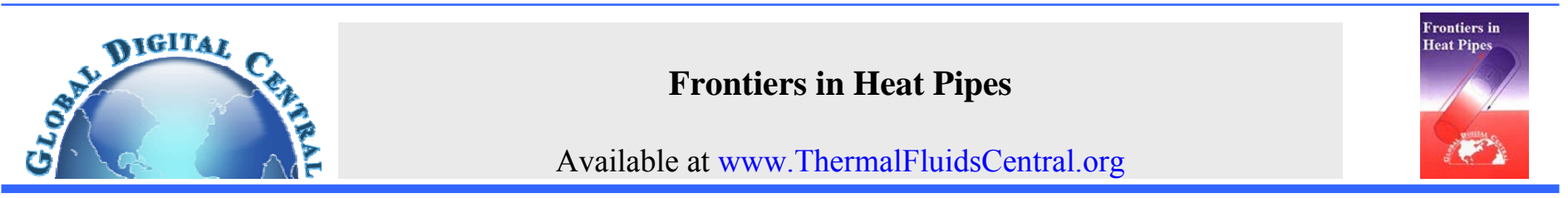

\title{
HEAT PIPES APPLICATION IN ELECTRONICS THERMAL CONTROL SYSTEMS
}

\author{
Sergii Khairnasov*, Alyona Naumova \\ Heat and Power Engineering Faculty, National Technical University of Ukraine "Kyiv Polytechnic Institute”, Kyiv, 03056, Ukraine
}

\begin{abstract}
Today widespread usage of cooling systems based on heat pipes contributes significantly to the ensuring of electronics thermal regulating conditions. The use of heat pipes as heat exchangers and heat transfer structural members allows creating a new generation of efficient heat removals on their basis. Today the following areas where heat pipes are widely used can be identified: computer equipment from small computers to large data centers, power electronics, and electronics for special purposes. The article analyzes the current state and prospects of using heat pipes in thermal control system of electronic equipment for ground applications.

Keywords: heat pipe, thermosyphon, electronics, computer equipment, cooling system.
\end{abstract}

\section{INTRODUCTION}

The problem of thermal control of electronics and electronic equipment intended for ground applications is very important issue. This is primarily associated with a fairly narrow temperature range of electronics' operation, which will ensure its nominal characteristics. In recent years, given problem is redoubled by the fact that new manufacturing technologies allow obtaining small size of electronic components. At the same time heat fluxes released by them are high enough. For example, this value for the AMD Trinity CPU core can reach up to $100 \mathrm{~W}$ with its area of $246 \mathrm{~mm}^{2}$, which complicates providing its thermal conditions. In addition, modern computer centers spend about half of the input energy for refrigeration and compressor plants. Singh et al. (2011) showed that the part of cooling spent on resource-saving systems becomes very noticeable. Today, there are a number of design decisions ensuring the desired temperature of electronics. Radiators, fans, and liquid cooling systems are often used for this purpose. However, Reay and Kew (2006) noted that the use of active and passive thermal control systems based on the heat pipes (HP) seems to be the most effective solution for a number of tasks.

Gnilichenko et al. (1999) showed that the use of the HP in the electronics thermal control systems in present time is rather widespread. A lot of works as long ago as 1970s were devoted to the HP application in electronics cooling systems. But the HP mass introduction into the electronic industry including computers began in the early 2000 s. So, today almost all notebooks include cooling system based on the HP. HP are used in electronics assemblies and blocks with high power elements. They can be used to remove heat from both the electronics' element unit and the group of electronic components.

There are a lot of publications in which the authors reveal various technical solutions for electronics thermal control systems based on the HP and discuss HP constructions themselves. However, it should be noted that number of publications summarizing the HP application in the electronics is not enough. The main purpose of the article is to show and reveal different designs of the HP for electronics thermal control systems as well as to analyze and summarize them. The article provides information on the use of the following heat pipes: constant conductance heat pipes (CCHP) (micro- and miniature heat pipes, vapor chambers, flat plate heat pipes, flexible heat pipes, conventional heat pipes), loop heat pipes, and pulsating heat pipes. It should be noted that thermosyphons (heat pipes without capillary structure) and CCHP that operate in a thermosyphon mode often can be used in electronics thermal control systems. In this case, fluid returns in the evaporation zone due to the gravitational force (gravity). It should also be mentioned that CCHP may include the following types of wick: sintered powder, mesh, metal fiber, and grooved.

\section{ELECTRONICS THERMAL CONTROL SYSTEMS}

HP are perspective for use in electronics thermal control systems in the following cases:

- the heat source (electronic component or group of electronic elements) is located at a distance from the place where it is necessary to provide heat sink;

- it is necessary to improve the compactness and reduce weight and power characteristics of the thermal control system and the whole product.

The following design approaches to the thermal control systems based on the HP can be distinguished:

1. Elements of electronics are mounted directly on the HP surface. Such a circuit design can be realized by using a heat-conducting electrical insulating layer between the HP and the electronic element. Constructively this may be fulfilled by using conventional heatconducting pastes or compounds (KPT-8, KTE-2 etc.).

2. Elements of electronics are mounted on the HP body through heat-conducting structural elements. This assembling is often used if the HP body's cross section has a circular shape. In such cases heat transmissions made of the metal plate are used.

Different types of the HP are used as elements of electronics thermal control systems. Usually they are of small size such as: micro

\footnotetext{
${ }^{*}$ Corresponding author. Email: sergey.khairnasov@gmail.com
} 
and miniature HP, vapor chambers, flat plate HP, flexible HP, round HP with different types of wick, loop HP, and pulsating HP.

Assembling of electronics with the HP may occur in different ways. The main factors that influence the design are:

- relative positioning of the elements dissipating heat and the area that removes heat to the environment;

- maximum heat output released by electronics' components;

- maximum and minimum temperature of the electronics' working elements;

- operating conditions of the electronics;

- other constructive issues.

Let's consider basic versions of thermal control systems for modern electronics that use HP taking into account information given by the company Furukawa (2014). Fig. 1 shows the basic circuit designs of the HP usage in such computer technology as laptop.

It should be noted that use of the HP for electronics cooling allows to increase efficiency of both active and passive cooling systems. This is the most often used approach that improves the efficiency of the active cooling system (Fig. 1, a) in laptop computer systems. In this case, use of the HP can improve assembling and reduce the weight and size characteristics of the product; increase the heat flux that can be removed from the product; and reduce the cost of the product. However, development of passive cooling systems (Fig. 1, b) is also promising. In this case, the body of a product, for example, back panel of the computer screen (Fig. 1, b) can be used as the radiator. First of all silence in products' operation as well as their reliability are provided. At the same time a problem of high heat fluxes removal may occur. This approach can be used in the systems with low heat generation (e.g. less than $10 \ldots 15 \mathrm{~W})$.

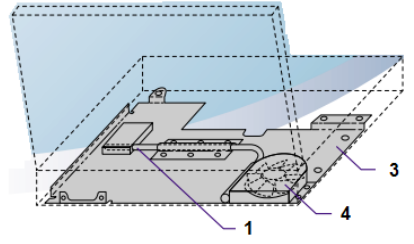

(a)

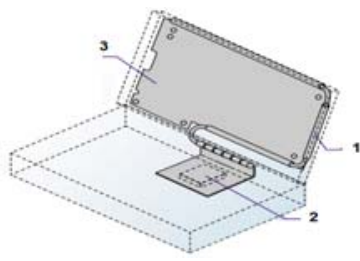

(b)
Fig. 1 Basic circuit designs using the HP for cooling of the laptop computer technology (Furukawa, 2014): a - scheme with an active cooling system; b - scheme with a passive cooling system; 1 - HP; 2 heat dissipating elements; 3 - the case or the board; 4 -radiator.

Similar approaches are implemented in thermal control systems intended for desktop computers (Fig. 2).

Computer processors based on the HP (Fig. 2, a) widely use radiators, for example, those produced by companies Cool Master, Zalman and many others. However, there are more opportunities to produce passive cooling system using HP for the mentioned types of computers. This is determined by larger surface of the product body. In this case the body is used as a heat sink of the passive cooling system and the HP serves as an element that transport heat from the processor to the body. As an example the body of Impactics C3LH \& K.ISS for home theater systems can be noted. This body has a passive cooling system with 4 copper HP. The system allows providing the required temperature conditions of the processor at its power of $35 \mathrm{~W}$ and a body temperature up to $50{ }^{\circ} \mathrm{C}$. The body dimensions are $260 \mathrm{~mm} \times 240 \mathrm{~mm} \times$ $8 \mathrm{~mm}$. The body also has two additional radiators.

The widespread use of the HP in electronics is not limited by only computers. Fig. 3 shows assemblies of the thermal control systems with the HP that are used in other electronic and radio-electronic systems.

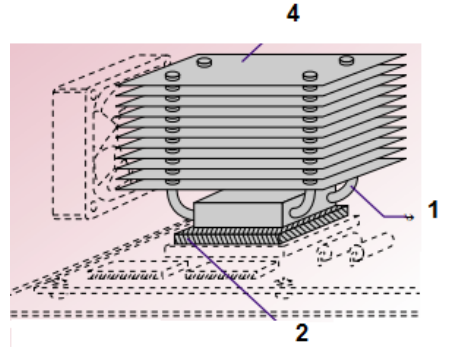

(a)

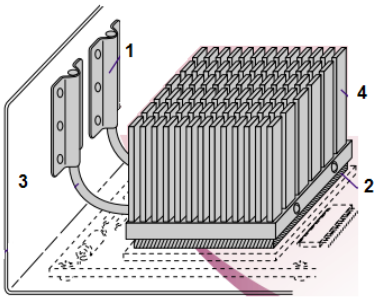

(b)
Fig. 2 Basic circuit designs using the HP for cooling of the desktop computer technology (Furukawa, 2014): a - scheme with an active cooling system; $b$ - scheme with a passive cooling system; 1 - HP; 2 heat dissipating elements; 3 - the case or the board; 4 - radiator.

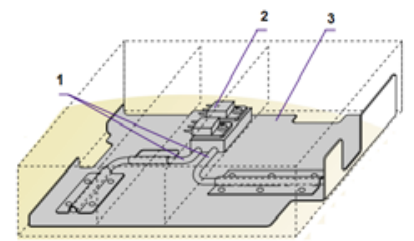

(a)

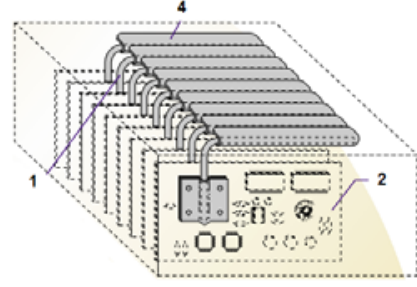

(c)

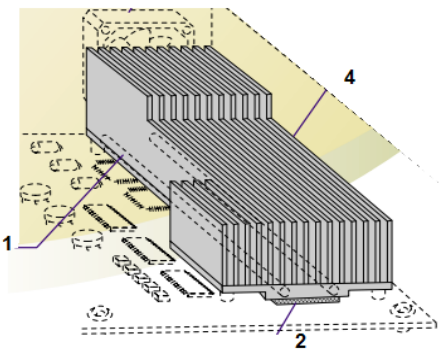

(e)

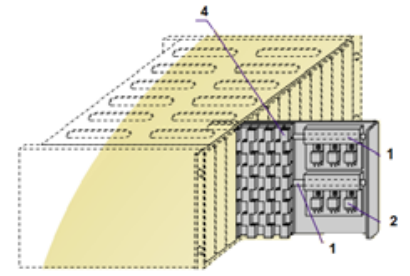

(b)

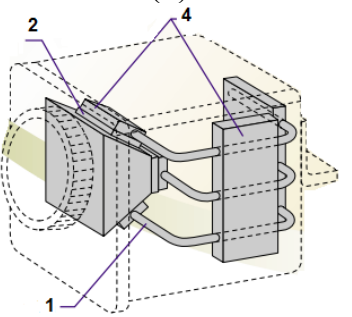

(d)

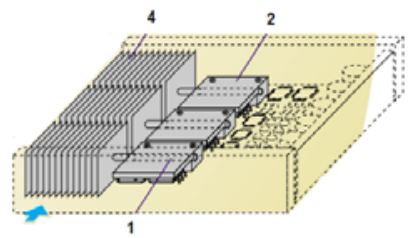

(f)
Fig. 3 Basic circuit designs using the HP in electronics thermal control systems (Furukawa, 2014): a - telecommunication units; b telecommunication converters; $\mathrm{c}$ - optoelectronic devices; $\mathrm{d}$ - cameras; e - workstations; f - servers.

Above all let's highlight the benefits and opportunities that can be provided by the HP. The main one is an ability to create a passive cooling system (Fig. 3, a). In this case, the product body or a special radiator board is used as an element of a heat sink. In addition, the HP use makes for the product compactness as it is shown by the example of telecommunication converter (Fig. 3, b). The use of the HP allows saving extra space for cooling air circulation between the boards. Another advantage of the HP usage is providing necessary thermal regime of products in cases when it is impossible to use active cooling system. Such examples are shown in Fig. 3, c and in Fig. 3, d. It should be noted that these approaches are often used in special-purpose electronics (e.g., military applications) and electronics working in a corrosive or flammable environment. HP are also used to reduce the noise of workstations and large computer centers (Fig. 3, e). The use of the HP can reduce the number of fans of the active cooling system and improve the mounting of the workstations' electronic components. But 
one of the main advantages of the HP is their ability to increase the efficiency of the cooling systems. Fig. 3, f presents an example of setting-up of thermal control systems for servers' processors. In addition to improving the electronic components' mounting the HP dramatically increase the surface of the heat sink through the effective use of larger radiators.

\section{HEAT PIPES APPLICATION}

\subsection{Micro- and miniature heat pipes}

The use of micro- and miniature round shaped HP is rather widespread today. Such structures have a diameter from 0.3 to $6 \mathrm{~mm}$. The HP body is made of copper; distilled water, ethanol, methanol or acetone can be used as a heat carrier. They can be made without wick thus functioning only in the thermosyphon (TS) mode. Micro- and miniature HP are also made with sintered powder, metal-fiber, mesh, and grooved wick. Fig. 4 shows various cooling systems using copper micro- and miniature HP.

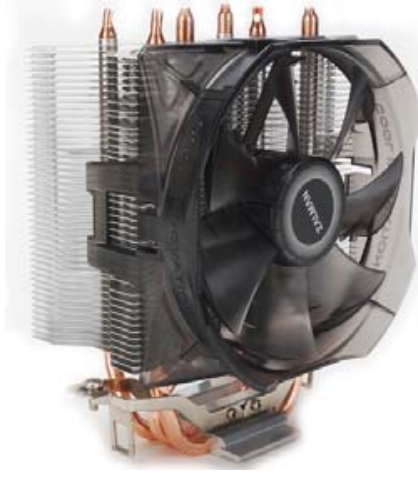

(a)

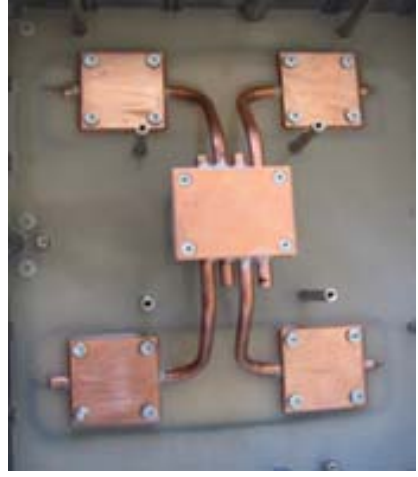

(b)

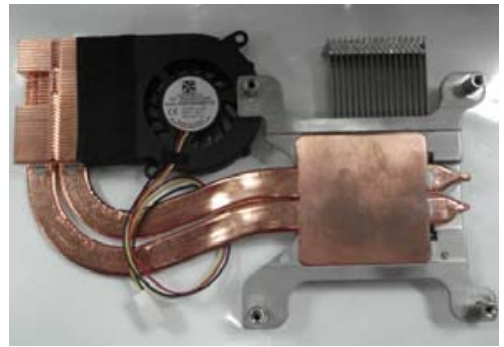

(c)

Fig. 4 Cooling systems based on copper micro- and miniature HP: a active cooling system for the desktop computer processor CNPS8X OPTIMA produced by company Zalman with three HP; b - passive cooling system for dashboard camera processor with four HP which was described by Kravets et al. (2013); c - active cooling system of the laptop computer processor with two flat plate HP.

Today, the technology of copper micro- and miniature HP manufacturing is widely developed. There are a number of theoretical models describing the processes inside such HP. A detailed theoretical analysis of the processes that take place in the evaporators and condensers of micro- and miniature HP is given by Badran et al. (1997) and Lallemand et al. (2004). There are a number of works devoted to the analysis of thermal control systems with the HP designed for the computers. Thus, a mathematical model and analysis of the temperature field of aluminum radiator with two and four built-in HP with a diameter of $6 \mathrm{~mm}$ are presented by Wang (2009). It is shown that two HP remove about $36 \%$ of the heat from the processor, and four HP can remove about $48 \%$. The total thermal resistance of the entire cooling system is $0.24{ }^{\circ} \mathrm{C} / \mathrm{W}$. Further development of this research given by Wang (2010) represents the calculating model for the radiators with built-in HP. Analysis of the results showed that the cooling system reaches its optimal characteristics when using the heat pipes with lengths of $210 \mathrm{~mm}$ (two HP) and $150 \mathrm{~mm}$ (four HP). Lefevre and Lallemand (2006) showed that the radiators with built-in HP have high efficiency and low cost when applied to the servers and computers. It works in cases when it is necessary to remove high heat fluxes from the electronic components at the same time maintaining their nominal temperature of $70{ }^{\circ} \mathrm{C}$. Ektummakij et al. (2004) presented advantages of the HP-based cooling systems intended for the laptops' processors produced by Fujikura.

The most prospective constructions of copper micro- and miniature HP contain sintered powder or metal-fiber wick. Thus, the use of the wick made of copper powders increases the heat transfer coefficients 3...4 times compared to the HP with grooved wick as it is shown by Vasiliev et al. (2002). For example Vasiliev (2005) presented HP with wick made of copper sintered powder (particles diameter is less than 100 microns) having total length of $200 \mathrm{~mm}$, evaporator length of 70 $\mathrm{mm}$, condenser length of $85 \mathrm{~mm}$, outer diameter of $4 \mathrm{~mm}$, and vapor channel diameter of $2 \mathrm{~mm}$, with water as a heat carrier. It transferred heat flux of $50 \mathrm{~W}$ in a horizontal position.

Vasiliev et al. (2002) compared efficiency of the powder wick, mesh wick, and wick fulfilled in the form of copper wire bundle in miniature HP. So under the same conditions and at a vapor temperature of $60{ }^{\circ} \mathrm{C}$ the HP with powder wick had maximum transferred heat flux of $35 \mathrm{~W}$, the same characteristic for the HP with a mesh wick was 28 $\mathrm{W}$, and for the HP with the wick fulfilled in the form of copper wire bundle it was $12 \mathrm{~W}$. At higher heat fluxes the difference was even higher.

Also, metal-fiber wick is promising for its application in micro- and miniature HP. The main advantage of such wick is its ability to provide the most efficient operation of the HP against gravity. It means that such HP can work effectively when heated area is located higher then the cooled one. Kravets et al. (2007) presented information that the HP with a length of $200 \mathrm{~mm}$, an outer diameter of $4 \mathrm{~mm}$, vapor channel diameter of $2 \mathrm{~mm}$, having a copper metal-fiber wick with a porosity of $82 \%$ and filled with water transferred about $5 \mathrm{~W}$ when working against gravity, about $55 \mathrm{~W}$ in a horizontal position, and more than $90 \mathrm{~W}$ when heat sink was higher then heat supply area. The HP with a length of 200 $\mathrm{mm}$, an outer diameter of $6 \mathrm{~mm}$, the diameter of the vapor channel of 3 $\mathrm{mm}$, having copper metal-fiber wick with a porosity of $70 \%$ and filled with water transferred respectively $60 \mathrm{~W}, 115 \mathrm{~W}$ and $250 \mathrm{~W}$. Thermal resistance of the HP was accordingly: $1.4 \ldots 1.5 \mathrm{~K} / \mathrm{W}$ for the HP with an outer diameter of $3 \mathrm{~mm}, 0.6 \ldots 0.8 \mathrm{~K} / \mathrm{W}$ for the $\mathrm{HP}$ with a diameter of 4 $\mathrm{mm}$, and $0.2 \ldots 0.3 \mathrm{~K} / \mathrm{W}$ for the HP with a diameter of $6 \mathrm{~mm}$.

\subsection{Vapor chambers}

The solution of electronics' thermal control problem at high heat flux density led to the creation of so-called vapor chambers. Vapor chamber (VC) is a flat miniature HP. The primary function of the VC is reducing the heat flux density by increasing heat dissipating surface. VC today are used as elements of radiators.

In the VC (Fig. 5) the vapor condenses on the surface with the heat removal system (e.g., radiator) mounted on it and returns to the evaporator under the influence of the mass forces or due to the wick. Wick allows the VC's functioning at any position, although its optimal characteristics correspond to the position when the condenser is located above the evaporator. Wei et al. (2006) showed that the sintered powder wick is most commonly used today in the VC.

The VC body additionally includes columns with the wick, which play the role of strength element in order to prevent squeezing of the $\mathrm{VC}$ body. These columns also increase the efficiency of the VC due to additional wick on them.

Main advantages of the $\mathrm{VC}$ lie in their high heat transfer rate at startup, low thermal resistance, and their ability to convert heat flux density. VC as well as the HP have the following defining characteristics: porosity of the wick, the pore size of the wick, the wick permeability, specific surface area, thermal conductivity and wetting of the surface by the working fluid. 


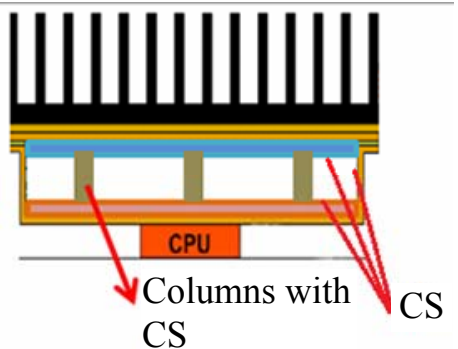

(a)

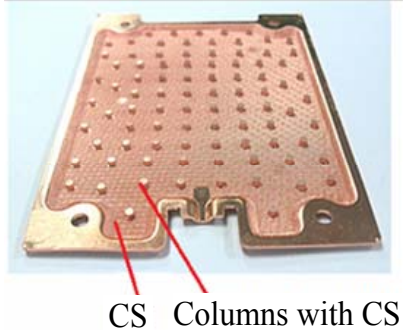

(b)
Fig. 5 Vapor chamber designed by company Cool Master: a - scheme; $\mathrm{b}$ - overview of the lower part (evaporator) of $\mathrm{VC}$.

Wei (2006) presented information that the use of the VC allowed to increase the efficiency of the active cooling system by $20 \%$ and reduce weight of powerful servers' thermal control system by $20 \%$. Lin J. showed that the $\mathrm{VC}$ can have effective thermal conductivity of about $800 \mathrm{~W} / \mathrm{m} \cdot{ }^{\circ} \mathrm{C}$, which is two times higher than that of pure copper. Wang et al. (2010) showed that the replacement of the conventional metal plate by VC in the GPU cooling system allowed to reduce its area and to increase power. The results showed that when the height of the fins between the VC and the fan was from $3 \mathrm{~mm}$ to $8 \mathrm{~mm}$ the system had optimal cooling characteristics, at that maximum heat flux density was $90 \mathrm{~W} / \mathrm{cm}^{2}$. Furthermore, when a copper radiator had 53 fins with a height of $3 \mathrm{~mm}$, a thickness of $0.2 \mathrm{~mm}$, and the distance between them of $1.0 \mathrm{~mm}$ the cooling system based on the $\mathrm{VC}$ had optimal thermal resistance of $0.265{ }^{\circ} \mathrm{C} / \mathrm{W}$. Koito et al. (2006) found out that the VC has the best weight/efficiency performance for integrated heat transfer system (IHS).

Today a series of works devoted to the wick development for the $\mathrm{VC}$ is carried out. For example, Yu et al. (2007) reported the results for the production of a new powder-based wick produced by metal injection molding method. The porosity of the wick was more than $53 \%$. The thermal conductivity of new VC was 20 times higher than that of the HP with a diameter of $10 \mathrm{~mm}$. Experimental data have shown that the use of this new VC increased cooling system's efficiency by $33 \%$.

The effectiveness of the VCs' use today is confirmed by numerous researches and mass production for server systems.

\subsection{Flat plate heat pipes}

Flat plate HP are at an early stage of wide implementation in electronics thermal control systems. They allow to remove heat from several elements at once. There is no need to provide special contact surfaces for round shaped HP. Today, both copper and aluminum HP are developed. Due to their small dimensions (height from $1 \mathrm{~mm}$ to $7 \mathrm{~mm}$ ) such HP often don't have wick.

Most of new researches are aimed at finding new materials for these HP. Wang et al. (2014) provided information on copper flat plate HP with silicone wick. The HP were designed for cooling of the elements (processors, LED power supply systems, and LED assemblies themselves) with a capacity of up to $10 \mathrm{~W}$. Flat plate HP had the following dimensions: $45 \mathrm{~mm}$ length, $16 \mathrm{~mm}$ width, and $1.5 \mathrm{~mm}$ height. The HP provided heat removal from the surface of $16 \mathrm{~mm} \times 16 \mathrm{~mm}$. The authors conducted a comparative analysis of a grooved copper wick and a silicone-based one. Efficiency of the HP with grooved copper wick was higher than that one on the basis of silicone by $17 \%$. Given research demonstrated the feasibility of the use of flat plate copper HP with copper and silicone grooves for LED cooling systems.

Use of non-metallic materials in flat plate HP is the most discussed topic today. However, such researches are conducting and are very promising. Cai et al (2010) provided information about the production of flat plate HP based on silicon. Carbon nanotubes were used as a wick. The wick was an array of nanotubes that formed grooves. Studies have shown that such HP can transfer $24 \mathrm{~W}$ at the heat flux density of $600 \mathrm{~W} / \mathrm{cm}^{2}$ in the horizontal position.
Also aluminum flat plate HP produced by company AmecThermasol (2014) without wick (Fig. 6) are used today in electronics components' cooling systems. Such HP filled with acetone can operate within a temperature range from $-40{ }^{\circ} \mathrm{C}$ to $+100{ }^{\circ} \mathrm{C}$ at tilt angles from 0 to $90^{\circ}$. These HP can have grooved wick, which allows their application at small tilt angles or in the horizontal position. HP are produced with the following dimensions (length $\mathrm{x}$ width $\mathrm{x}$ height): from $200 \mathrm{~mm} \times 20 \mathrm{~mm} \times 1.2 \mathrm{~mm}$ with a maximum transferred heat power of $5 \ldots 18 \mathrm{~W}$ (depending on the tilt angle and length) up to $500 \mathrm{~mm} \times 50$ $\mathrm{mm} \times 2.5 \mathrm{~mm}$ with a maximum transferred heat power of $75 \ldots 270 \mathrm{~W}$ (depending on the tilt angle and length). The main advantage of mentioned HP is their ability to provide complex forms of cooling systems (Fig. 6, b). HP are designed for cooling of the following elements: CPU and GPU, FBDIMM and UDIMM memory cards, lighting systems, optical communication modules, telecommunications network equipment, and high power electronic modules.

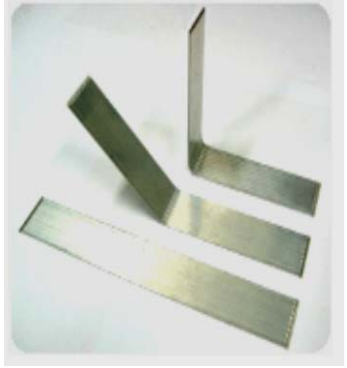

(a)

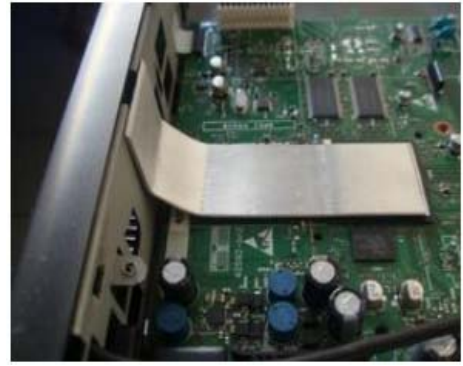

(b)
Fig. 6 AmecThermasol aluminum flat plate HP: a - general view; $b$ application in computer technology.

\subsection{Flexible heat pipes}

The first information on the approach to the flexible HP creation appeared due to Bliss et al. (1970). Given HP was made of a metal tube (the material was stainless steel) with an inner diameter of $25.4 \mathrm{~mm}$ and a total length of $311 \mathrm{~mm}$. The corrugated pipe was used in the adiabatic zone to provide flexibility. The four-layer mesh wick was made of stainless steel. The water was used as a heat carrier. First commercial flexible HP for ground application appeared in the 2000s. So in 2004 the company Furukawa (2004) introduced a flexible HP «Pera-flex» made of metal foil sheet and tampon coating covered with a special material to increase its wettability. The HP had a thickness of $0.7 \mathrm{~mm}$, a length of $150 \mathrm{~mm}$ and a width of $20 \mathrm{~mm}$. The thermal resistance was $1.0 \mathrm{~K} / \mathrm{W}$ for transferred power of $4 \mathrm{~W}$. Bending tests have shown that the HP had a heat transfer capacity of $6 \mathrm{~W}$ at bend angle of $90^{\circ}$ and bend radius of $10 \mathrm{~mm}$.

Recently development of flexible HP causes constantly growing interest. Oshman et al. (2004) presented the results of research and development of polymer flexible flat plate HP with dimensions of 130 $\mathrm{mm} \times 70 \mathrm{~mm} \times 1.31 \mathrm{~mm}$ (Fig. 7). The HP body was a set of sheets made of polyethyleneterephthalate, aluminum, and polyethylene. The wick was manufactured by a three-layer mesh sintering. The working fluid used was water. The temperature difference between the evaporator and condenser at $25 \mathrm{~W}$ was $1 / 4$ of temperature drop of the copper plate with the same dimensions. Neglecting thermal resistance of polymer layers the thermal conductivity of this HP was 4.6 times higher than that one of a copper plate sample having similar dimensions. In addition, the HP weight was 9.5 grams, which was $1 / 5$ of the copper plate mass.

Wu et al. (2011) presented the experimental results for the polymer HP with copper mesh wick filled with methanol. To reduce thermal resistance of the evaporator the HP body in this zone was partly made of copper foil. The HP had a thickness of $1.8 \mathrm{~mm}$ and allowed bending at an angle of 45 degrees, while providing the transfer of heat flux up to $30 \mathrm{~W}$. Thermal resistance of the $\mathrm{HP}$ was $0.157 \mathrm{~K} / \mathrm{W}$ at transferred heat flow of $25 \mathrm{~W}$. 
polyethylenetherephthalate, aluminum and polyethylene layers

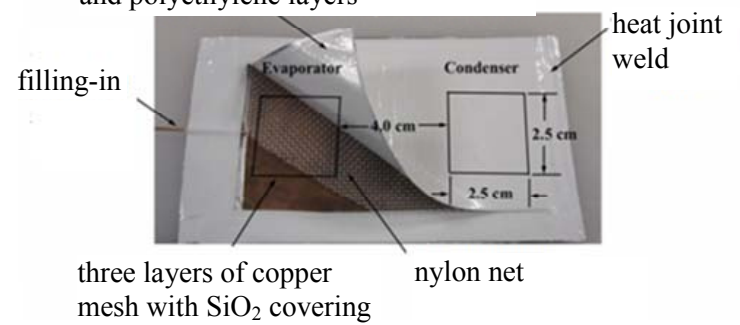

Fig. 7 Polymeric flexible HP (Oshman et al., 2004).

Flexible HP development trend today is promising. Moreover, this research area is directed primarily to the use of nonmetallic materials for the HP, which is also promising.

\subsection{Loop heat pipes}

Loop heat pipe (LHP) is a passive two-phase system with capillary pumping of the fluid. Huang et al. (2004) and Maydanik et al. (2005) showed that modern LHP attract attention as very efficient heat transfer devices for electronics thermal control systems. Known LHP use a variety of different materials and coolants such as: stainless steel, copper, ceramics, ammonia, water, methanol, ethanol, and Freons. They can be considered as elements of electronics cooling systems. Researchers pay special attention to copper LHP filled with water when it comes to the cooling systems of computer elements. Both of these materials are inexpensive and available.

The constructive scheme of LHP application in electronics thermal control systems is shown in Fig. 8. The main advantages of the LHP are as follows: operating of cooling system in any orientation in space without substantial changing of its characteristics; ability to work in moving systems for large values of $\mathrm{g}$ ( 5 or more); ability to provide a flexible connection between heat supply and heat sink areas.

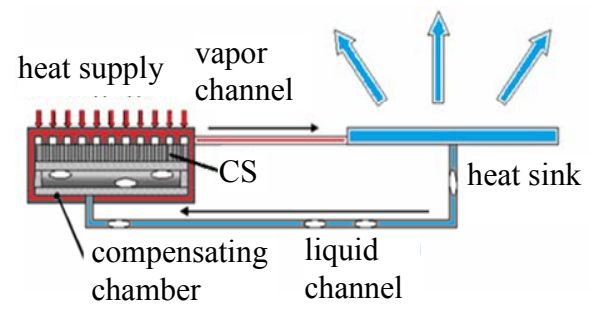

(a)

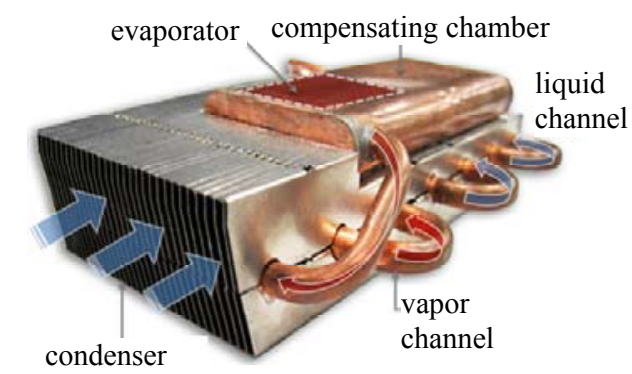

(b)

Fig. 8 Thermal control system based on the LHP: a - scheme; $b$ - the Cool Master product overview.

Zimbeck et al. (2008) provides information on copper LHP with ceramic wick that use water as the working fluid. These LHP were tested for cooling of processors with a capacity of $100 \mathrm{~W}$. Singh et al. (2007) provided data on copper LHP with the evaporator having a disk shape with a diameter of $30 \mathrm{~mm}$ and a height of $10 \mathrm{~mm}$. This LHP was air-cooled and removed heat flux of $70 \mathrm{~W}$.

It was shown by Maydanik et al. (2005) that LHP have great potential for use in the cooling systems of electronics that has small dimensions. However LHP application is perspective not only in miniature electronics but also in power electronics and electronic systems with high capacity. Concerning this field LHP may engage in competition with water cooling systems designed for high-powered electronics. Calyos Company presented LHP design that allows building them in the cooling system of servers and supercomputers (Fig. 9). In this case, LHP remove the heat flow outside the working space of the electronic unit to an external heat sink. Chernysheva et al. (2014) noted that it is possible to organize the systems with heat recovery for buildings' heating. They showed one variant of practical application of copper LHP filled with water intended to cool the CPU and GPU and revealed the expediency and prospects of using of such systems. Results of the analysis and testing of the supercomputers' cooling system based on two copper LHP filled with water are presented. Effective LHP length was $400 \mathrm{~mm}$. The evaporator had a thickness of $7 \mathrm{~mm}$, a length of $80 \mathrm{~mm}$, and a width of $42 \mathrm{~mm}$. Tests were carried out in the range of cooling liquid temperatures from $20{ }^{\circ} \mathrm{C}$ to $80{ }^{\circ} \mathrm{C}$ and heat supply powers from 20 to $600 \mathrm{~W}$.

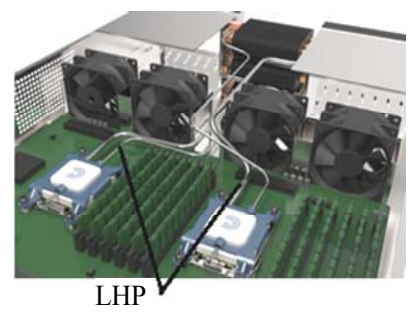

(a)

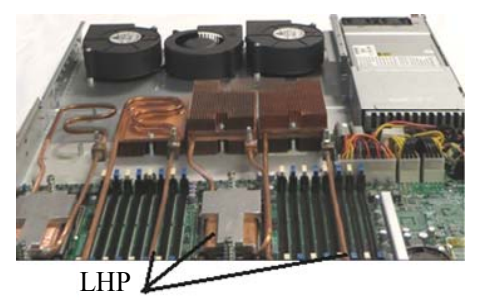

(b)
Fig. 9 Calyos design of the cooling systems with LHP for servers and supercomputers.

Loop thermosyphons have also achieved wide application. Actually they represent LHP in which the condenser is located above the evaporator. Loop thermosyphons in the future may use flexible evaporators since their evaporators don't have to satisfy any high requirements. Such constructions can be used in the cooling systems of power electronics. For example, Sukhvinder (2012) presented information about application of the loop thermosyphons in the cooling system of IGBT transistors with total heat power dissipation up to $2 \mathrm{~kW}$ and heat flux density of $10 \mathrm{~W} / \mathrm{cm}^{2}$.

LHP have good prospects for use in electronics thermal control systems in the future. This concerns both miniature devices (computer equipment) and high-powered electronics. Moreover, such constructions (except the loop thermosyphons) allow their use in moving systems and systems changing their orientation in space. It should also be noted that LHP are promising for use in cooling systems of data centers, followed by heat recovery for buildings' heating.

\subsection{Pulsating heat pipes}

Pulsating heat pipes (PHP) (fig. 10) are considered now as a promising new type of the HP that can be used in electronics thermal control systems. However, it is too early to talk about their mass production. Study of these HP is continuing and it is primarily directed on their stable operation and development of calculation methods.

Main advantage of PHP is that they have no capillary structure. This allows reducing their manufacture process cost. They can operate at any orientation in space. In addition, given the fact that the PHP body consists of a tube with outer diameter of $2 \ldots 4 \mathrm{~mm}$ and the whole PHP construction is a number of loops forming rather effective heat removing surface there is no need to use additional radiators. 


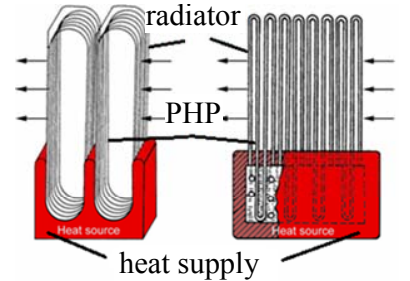

(a)

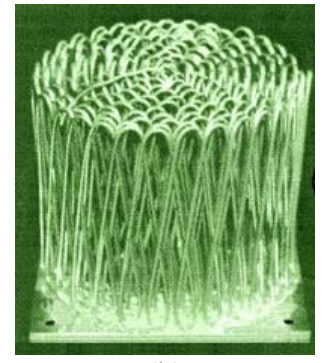

(b)

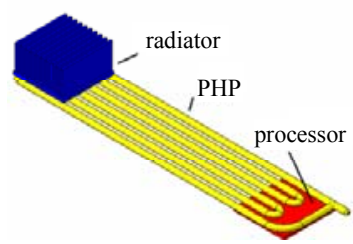

(c)

Fig. 10 Radiators based on the PHP: a - design; b - radiator overview; c - example of circuit design for PHP application in miniature electronics.

Over the past 10-15 years, researches all over the world made a sufficient number of experimental and theoretical studies that confirmed the PHP efficiency. Analysis of the processes that take place inside PHP and stages of their development are given by Zhang and Faghri (2008). Today it is known that the choice of the design parameters, types of materials, and heat carriers are the key factors affecting the PHP efficiency. These factors include geometry, number of turns, total tube length, tube diameter, length of the evaporator and the condenser. Stainless steel and copper are now primarily considered as the material for the PHP body. The literature provides information on various heat carriers for PHP. Khandekar (2004) and Wilson et al. (2011) presented information about PHP with water, Wilson et al. (2011) presented information about PHP with acetone, Khandekar (2004) and Naphon (2009) presented information about PHP with Freons. In addition Wang et al. (2009) and Wang et al. (2009) analyzed the PHP with liquids which included micro particles (nanofluids). Niloofar Mohammadi et al. (2012) showed that nanofluids can significantly improve the PHP performance. The use of the nanofluids, e.g. $\mathrm{Al}_{2} \mathrm{O}_{3}$ in water, can reduce thermal resistance of the solid surface by $30 \%$ compared with distilled water. It is noted that optimal filling ratio for nanofluids (water and silver powder) is $50 \%$ of the PHP internal volume. At that thermal resistance of the PHP is $0.9 \mathrm{~K} / \mathrm{W}$. Optimal filling ratio for water with titanium oxide powder was $40 \%$. For this case the PHP thermal resistance was $0.8 \mathrm{~K} / \mathrm{W}$. For comparison, thermal resistance of similar PHP filled with distilled water was 1.15 $\mathrm{K} / \mathrm{W}$.

Radiators for IGBT elements (Fig. 10, a) can be given as an example of the PHP use in electronics cooling systems. Akachi and Polasek (1998) described the radiator (Fig. 10, b) with dimensions of 80 $\mathrm{mm} \times 80 \mathrm{~mm}$ that transferred heat flux of $450 \mathrm{~W}$, and at the cooling air velocity of $3 \mathrm{~m} / \mathrm{s}$ had a thermal resistance of $0.089 \mathrm{~K} / \mathrm{W}$. PHP was made of a tube with an outer diameter of $1.6 \mathrm{~mm}$, inner diameter of 1.2 $\mathrm{mm}$ and had 500 loops. Also, the Japanese company TS-Heatronics has developed the radiators "HeatLine" and "Kenzan". When developing radiators next combinations of the body materials and heat carriers were tested by Akachi and Polasek (1998): stainless steel with nitrogen, copper with water, methanol, R-113 and R-142b, aluminum with R$142 \mathrm{~b}$. Typical thermal resistance for the radiator "Kenzan" with dimensions of $60 \mathrm{~mm} \times 60 \mathrm{~mm} \times 65 \mathrm{~mm}$, which was made of a copper tube (with outer diameter of $1.0 \mathrm{~mm}$, inner diameter of $0.7 \mathrm{~mm}$, and number of loops 152), filled with R-142b, and cooled by convection with an air speed of $3 \mathrm{~m} / \mathrm{s}$ was $0.3 \mathrm{~K} / \mathrm{W}$. Circuit design shown in Fig. $11, \mathrm{c}$ can be used in computers and miniature electronics.

It should be noted that PHP can function not only in any orientation in space, but also under acceleration. For example, the PHP with dimensions of $30 \mathrm{~mm} \times 30 \mathrm{~mm}$ transferred heat flux of $100 \mathrm{~W}$ at acceleration of $10 \mathrm{~g}$ and at heat-supply density of $33 \mathrm{~W} / \mathrm{cm}^{2}$.

Thus, PHP are perspective devices for electronics thermal control systems that can be widely used in the future after developing their production technology.

\subsection{The use of conventional heat pipes}

Conventional HP and thermosyphons are widely used today in a variety of electronics thermal control systems with power output of $50 \mathrm{~W}$ and above. There are many different kinds of thermal control systems in this area that contain copper and steel HP with and without wick (fig. 11, a, b) as well as aluminum HP with grooved wick (fig. 11, c) operating in thermosyphons modes.

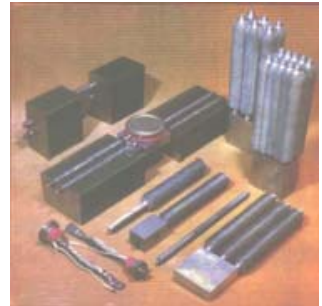

(a)

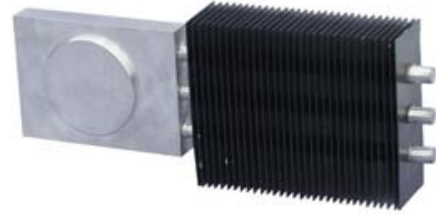

(b)

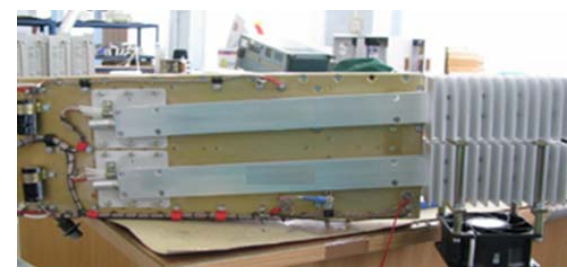

(c)

Fig. 11 Radiators based on conventional HP: a - based on copper and steel HP produced by Powder Metallurgy Institute; $b$ - based on copper HP produced by DAU Company; c - based on aluminum HP with grooved wick.

So radiators produced in the Powder Metallurgy Institute (Belarus) include copper HP with diameters ranging from $3 \mathrm{~mm}$ to $20 \mathrm{~mm}$, length of $720 \mathrm{~mm}$, maximum transferred heat flux of up to $500 \mathrm{~W}$, with powder wick and without any. Water, ethanol, and methanol are used as the heat carriers. These radiators can remove heat fluxes up to $4000 \mathrm{~W}$.

DAU Company offers a variety of cooling systems based on the heat pipes. Depending on the operating conditions and the desired characteristics different HP may be used in the systems, for example filled with water for operating temperatures from +5 to $+275{ }^{\circ} \mathrm{C}$ and filled with methanol for temperature range from -40 to $+80{ }^{\circ} \mathrm{C}$. Aluminum, stainless steel, and copper are used as the materials for the HP body. These radiators can provide a heat dissipation of $1000 \mathrm{~W}$ and more.

Khairnasov et al. (2014) showed that aluminum HP with grooved wick are also promising for cooling of special-purpose ground electronics systems (fig. 11, c). Ammonia, acetone, and pentane can be used as the heat carriers in such HP. Special-purpose systems make high demands on the HP. Thus, for example, aluminum HP operating in the thermosyphons mode with a diameter of $12.5 \mathrm{~mm}$ and filled with ammonia can have temperature drop no more than $2{ }^{\circ} \mathrm{C}$ at transferred heat flux of $150 \mathrm{~W}$ in the temperature range from $-40{ }^{\circ} \mathrm{C}$ to $+100{ }^{\circ} \mathrm{C}$. Aluminum HP can be widely used in thermal control systems of electronic devices located in a sealed housing. It is known that such devices work in harsh environments, in fire and explosive places. The main problem is inability to organize intensive cooling of electronic components inside such devices. In this case heat is removed from 
heated elements to the device body, which serves as a radiator. Rassamakin et al. (2009) showed that these HP were used in the cooling systems intended for radio-equipment cabinets in the sea and river transport. Cooling system ensured functioning of the radio-equipment cabinet at heat input range from 500 to $3600 \mathrm{~W}$ for the radio-equipment cabinet section simulator and from 710 to $4330 \mathrm{~W}$ for multi-section cabinet of electronic components simulator. The inlet cooling water temperature was $6 \ldots 23^{\circ} \mathrm{C}$ and at the tilt angle was $0^{\circ} \ldots 15^{\circ}$.

Today copper HP are attached to the radiators using heat conductive paste, solder or conventional pressure contact. However, development of radiators with built-in HP (Fig. 12) is a promising direction. Such radiators can be used in power electronics. Given construction consists of the HP with a diameter of $8 \mathrm{~mm}$ and a length of $300 \mathrm{~mm}$. Each HP can transfer heat flux up to $70 \mathrm{~W}$.

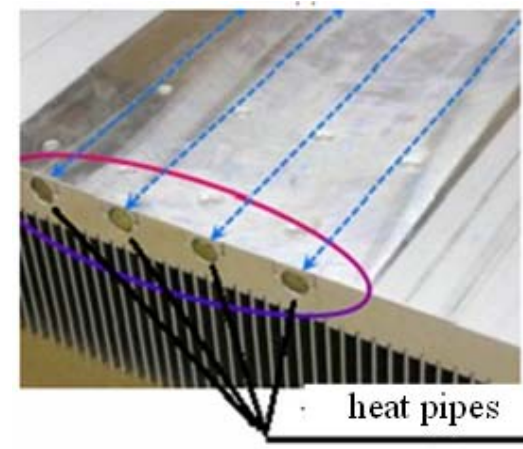

Fig. 12 Radiators with built-in HP by company Hill Tech Sales.

In the long term manufacturing of radiators with the HP having diameter of $16 \mathrm{~mm}$ is considered. In this case, each HP will be able to transfer up to $1 \mathrm{~kW}$ and the entire assembly will transfer up to $32 \mathrm{~kW}$.

\section{R\&D PROGRESS AND OPPORTUNITIES FOR FURTHER WORKS}

Thus, today different types of the HP are used in the electronics. Let's generalize the HPs' heat transfer characteristics and consider their prospects and ways of their improving. Table 1 and 2 shows a summary of information that characterizes features of the considered types of the HP.

\section{Micro- and miniature heat pipes.}

As noted above manufacturing technology of such HP today is quite developed. However, there are a number of promising areas for further research and technological development:

1. First of all, reducing the diameter of the heat pipes greatly reduces their productivity. It can be explained by the processes that take place in constraint conditions, which impose a number of restrictions on the HP functioning. So reducing of the outer diameter of the copper HP with metal-fiber wick from $6 \mathrm{~mm}$ to $3 \mathrm{~mm}$ increases its thermal resistance more than 5 times. Usually, micro and miniature heat pipes with an outer diameter of less than $4 \mathrm{~mm}$ are characterized by high thermal resistance that is more than $1 \mathrm{~K} / \mathrm{W}$ and low values of transferred heat fluxes that are less than $20 \ldots 30 \mathrm{~W}$. Fundamental studies of thermal-hydraulic processes including boiling and condensation in such confined spaces can open up new ways of increasing the effectiveness of micro and miniature HP in the future.

2. Almost all works today are devoted to micro- and miniature HP made of copper. It results from high manufacturability of the HP and compatibility of copper with water and alcohols. However, to the date aluminum grooved HP with diameters greater than $5 \mathrm{~mm}$ are widely used in space technology. Such HP provide low thermal resistance (less than $0.05 \mathrm{~K} / \mathrm{W}$ ) and high values of maximum heat transfer ability that are up to $12 \mathrm{~W} \cdot \mathrm{m}$ at horizontal location (Miao, 2007). Creation of the AGHP with an external diameter of less than $5 \mathrm{~mm}$ can increase the effectiveness of electronics thermal stabilization systems as well as to improve their dimensions and weight characteristics.

\section{Vapor chambers.}

Given technology is primarily directed to the use in a PC for example laptop and desktop. The main problem for today lies in reduction of $\mathrm{VC}$ height to $1 \mathrm{~mm}$ or less, taking into consideration the prospects of their use in tablets and mobile phones. As in the case of miniature and micro- HP downsizing dramatically decreases transferred heat fluxes and increases thermal resistance. Thus, the following areas of research seem to be promising:

1. Research of the processes and intensification of heat and mass transfer in the VC with a height of $1 \mathrm{~mm}$ or less through the development of new wicks and heat transfer surfaces. In particular, metal-fiber wicks which are currently not used have good prospects of application in such constructions.

2. Search for non-metallic materials for manufacturing of bodies and wick that ensure long service life under contact with the heat carrier and provide vacuum leak-proofness.

\section{Flat plate heat pipes.}

Development of flat plate HP today offers the challenge to improve the compactness and to reduce weight and size of electronic equipment. There are examples of flat plate heat pipes made of copper and aluminum. But given the prospect of the use of such HP for heat dissipation from several sources the main task is to reduce their height to $2 \mathrm{~mm}$ or less at maintaining their high efficiency. That opens the potential for their use in tablets, mobile phones and other similar devices. In this direction it is urgent to find solutions that will reduce hydraulic losses in the flat plate HP due to the separation of liquid and vapor flows, using new types of wicks or inner cross section shapes of steam and liquid channels (for example using grooved wick).

\section{Flexible heat pipes.}

Although the design of flexible HP is known for a long time, development of non-metallic constructions is a promising direction. Today there are experimental samples of polymer flat plate HP. However, there is no information about one of their main characteristics which is their life time. Thus, given the prospect of the use of such HP in tablets, mobile phones and similar micro-electronic devices, the following areas are perspective:

1. Search for non-metallic materials and their combinations for manufacturing of bodies and wick that ensure long service life of the HP.

2. Study of the properties of new non-metallic materials intended for the HP manufacturing, primarily, their wettability.

3. Testing the sealing of considered HP, thus solving the problem of the housing reliability under internal overpressure.

In addition the development of metal design of flexible flat HP is a promising too. In this case the metal foil (stainless steel or cooper) and mesh (stainless steel or cooper/brass) could be used. But for all that the problem of the housing reliability under internal overpressure must be solved.

\section{Loop heat pipes.}

Known designs of the LHP for electronics thermal control systems have the height of the heating area (evaporator) not less than $7 \mathrm{~mm}$. Thus the main problem of their manufacture lies in providing stable work that involves both internal LHP processes and cross-flow of the heat along the body from the evaporator to the compensation cavity. Evaporator downsizing affects these processes adversely.

Thus, preserving of the LHP efficiency simultaneously with evaporator downsizing through the use of new body designs (including materials of low thermal conductivity), capillary pumps (particularly, metal-fibrous), and methods of their arrangement is an urgent task 
Table 1 The evaluative generalization of HP's in according with their main operating characteristics.

\begin{tabular}{|c|c|c|c|c|c|c|c|c|c|c|c|c|c|}
\hline 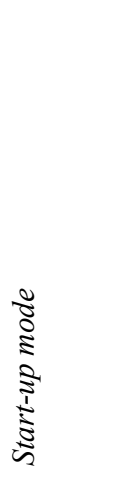 & \multicolumn{4}{|l|}{ 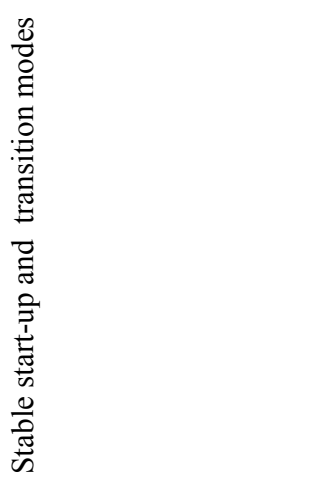 } & 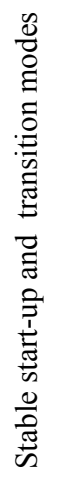 & 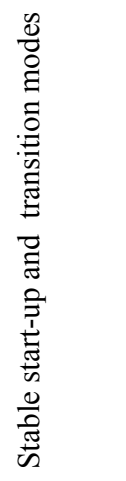 & , & 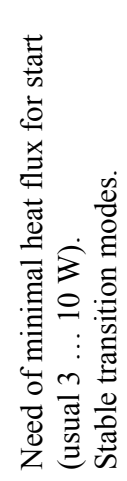 & 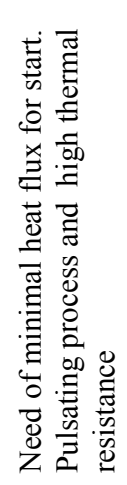 & \multicolumn{4}{|l|}{ 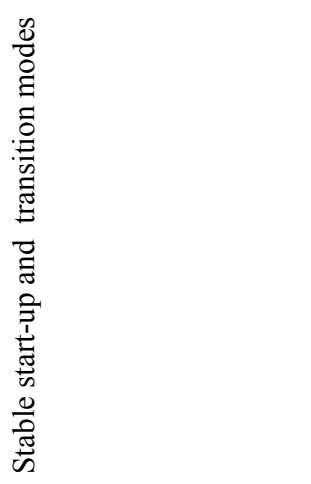 } \\
\hline 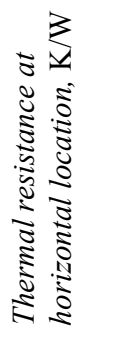 & \multicolumn{4}{|l|}{\begin{tabular}{l}
\multirow{1}{0}{} \\
$\wedge$
\end{tabular}} & $\begin{array}{l}\sim \\
0 \\
\wedge\end{array}$ & ' & $\stackrel{\stackrel{O}{-}}{\wedge}$ & $\begin{array}{l}\hat{0} \\
0 \\
1\end{array}$ & $\begin{array}{l}\overrightarrow{0} \\
\wedge\end{array}$ & \multicolumn{4}{|l|}{$\begin{array}{l}\widetilde{\delta} \\
0 \\
\wedge\end{array}$} \\
\hline 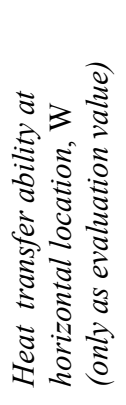 & \multicolumn{4}{|c|}{ 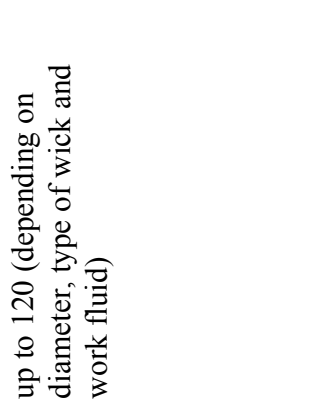 } & 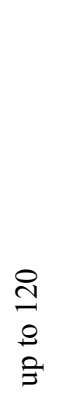 & 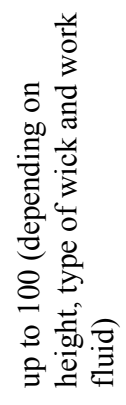 & 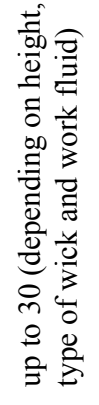 & $\begin{array}{l}8 \\
0 \\
0 \\
3\end{array}$ & $\begin{array}{l}8 \\
0 \\
0 \\
\vdots \\
3\end{array}$ & \multicolumn{4}{|c|}{ 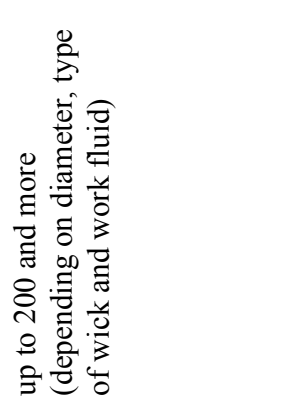 } \\
\hline 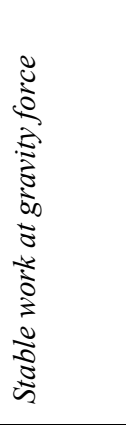 & 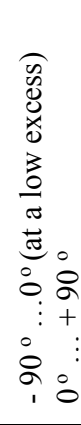 & $\begin{array}{c}: \\
8 \\
+ \\
\vdots \\
\vdots\end{array}$ & 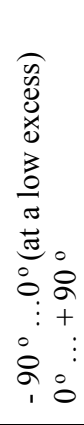 & $\begin{array}{c}0 \\
8 \\
+ \\
\vdots \\
\vdots\end{array}$ & 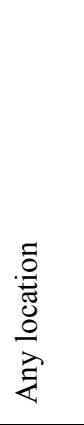 & 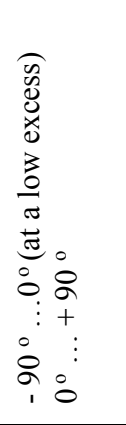 & $\begin{array}{c}\dot{8} \\
\therefore \\
+ \\
\vdots \\
\vdots \\
0\end{array}$ & 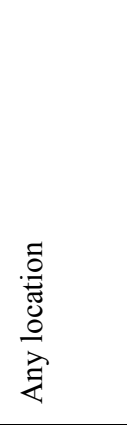 & 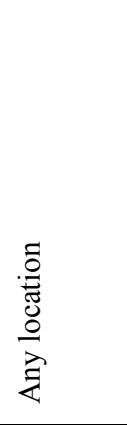 & 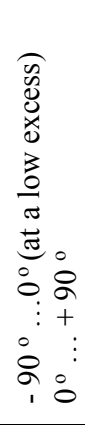 & $\begin{array}{c}0 \\
8 \\
+ \\
\vdots \\
\vdots\end{array}$ & 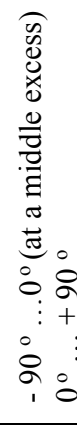 & $\begin{array}{l}\circ \\
8 \\
+ \\
\vdots \\
\vdots\end{array}$ \\
\hline 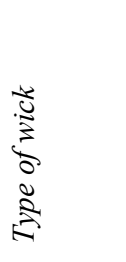 & 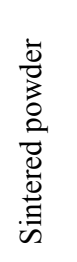 & $\sum^{\tilde{y}}$ & 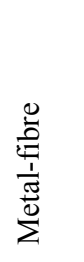 & $\begin{array}{l}\vec{D} \\
\stackrel{0}{0} \\
\stackrel{0}{0}\end{array}$ & 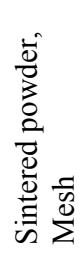 & 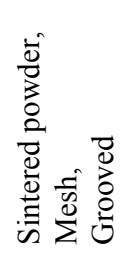 & 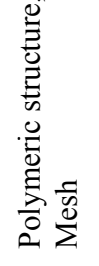 & 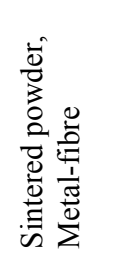 & ' & 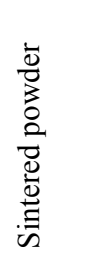 & $\frac{\bar{g}}{\sum^{e}}$ & 竞 & $\begin{array}{l}\bar{\Xi} \\
\text { ठे } \\
\dot{0}\end{array}$ \\
\hline 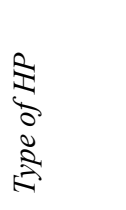 & 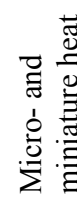 & & & & 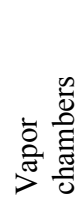 & 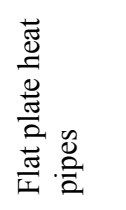 & 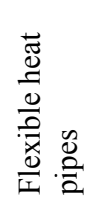 & 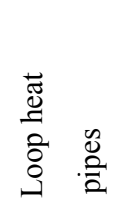 & 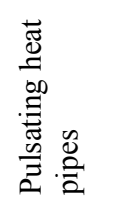 & 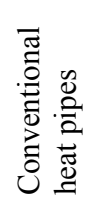 & & & \\
\hline
\end{tabular}


Table 2 The generalization of experimental data of HP for the electronics thermal control systems.

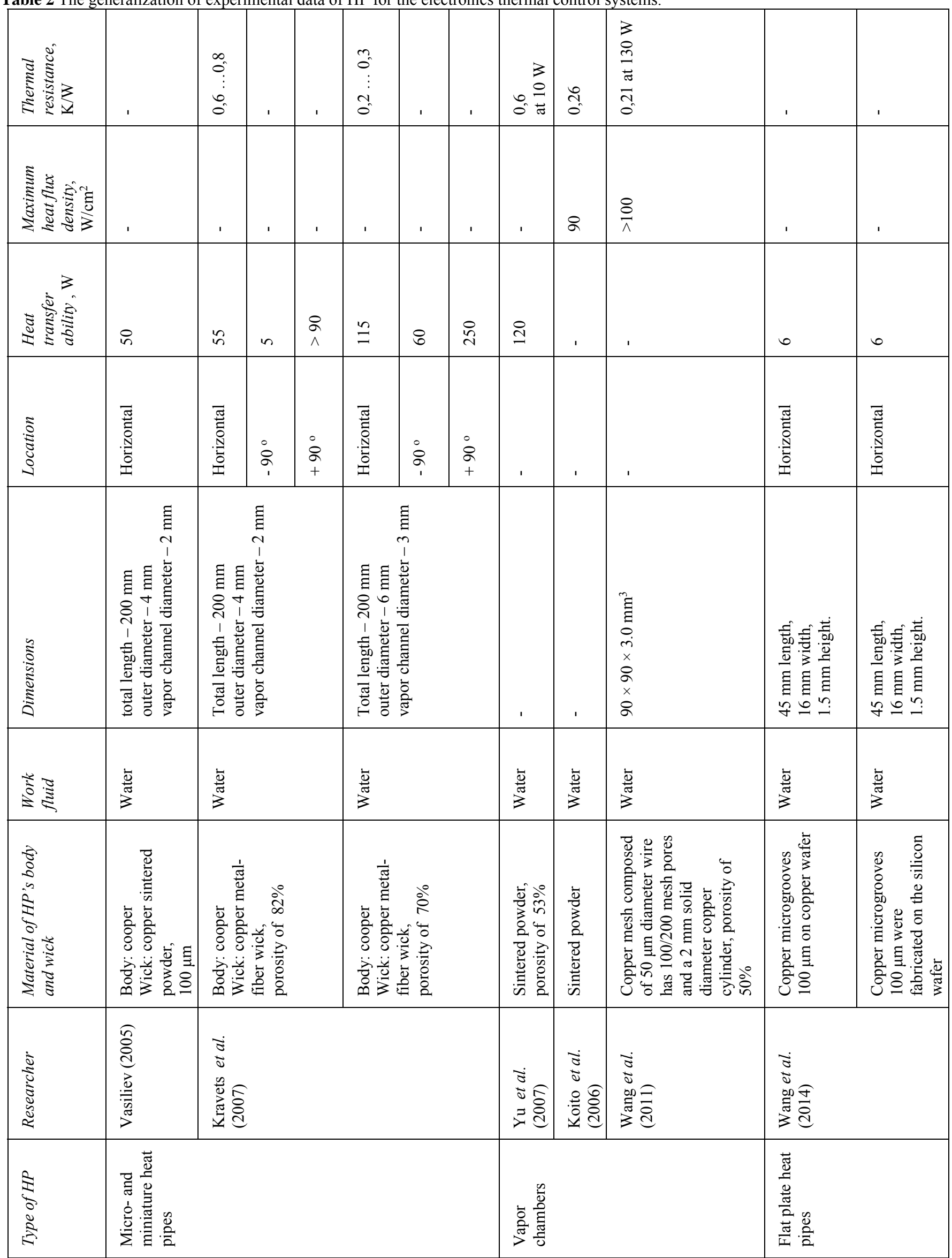


Table 2 (continuation)

\begin{tabular}{|c|c|c|c|c|c|c|c|c|c|c|c|c|c|}
\hline 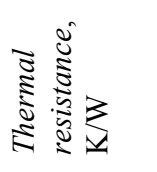 & , & ' & ' & $\stackrel{\circ}{\rightarrow}$ & $\stackrel{\Xi}{-}$ & $\stackrel{\infty}{\rightarrow}$ & $\frac{i n}{0}$ & ' & , & $\hat{o}$ & $n$ & $\stackrel{\simeq}{\circ}$ & $\overrightarrow{0}$ \\
\hline 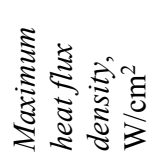 & 8 & ' & ' & , & , & , & ' & ' & , & I & , & $\stackrel{\vec{N}}{\vec{N}}$ & $\begin{array}{l}\ddot{n} \\
\dot{n}\end{array}$ \\
\hline 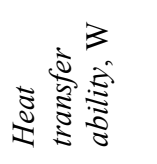 & $\stackrel{\sim}{\sim}$ & $\begin{array}{c}3 \\
\infty \\
\vdots \\
\vdots \\
n\end{array}$ & 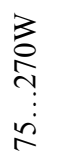 & $\nabla$ & $\begin{array}{l}n \\
\tilde{c}\end{array}$ & $\begin{array}{l}n \\
\text { हn }\end{array}$ & $\approx$ & $\stackrel{R}{R}$ & $\begin{array}{c}8 \\
8 \\
\vdots \\
i\end{array}$ & $\begin{array}{l}\stackrel{\circ}{7} \\
\frac{1}{2}\end{array}$ & in & $\approx$ & 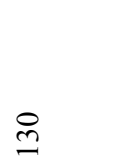 \\
\hline 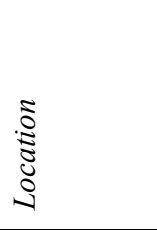 & 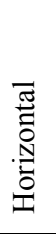 & $\begin{array}{c}0 \\
8 \\
+ \\
\vdots \\
\vdots \\
0\end{array}$ & $\begin{array}{l}0 \\
8 \\
+ \\
\vdots \\
\vdots \\
0\end{array}$ & 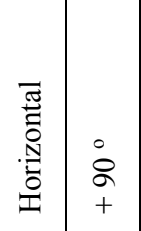 & 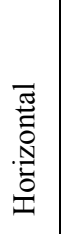 & $\begin{array}{l}i n \\
i \\
+\end{array}$ & $\begin{array}{l}i n \\
\text { in } \\
+\end{array}$ & 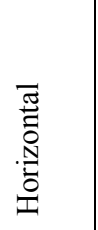 & 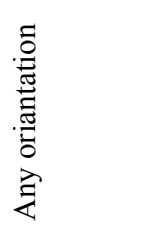 & 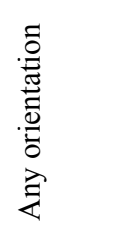 & , & , & 1 \\
\hline $\begin{array}{l}\vdots \\
\vdots \\
\vdots \\
\vdots \\
\vdots \\
\vdots \\
\vdots\end{array}$ & ' & 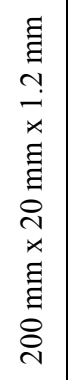 & 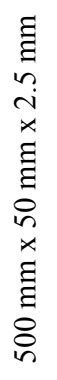 & 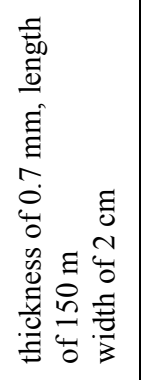 & 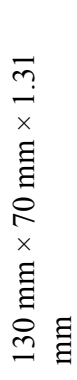 & & 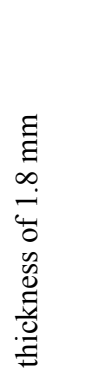 & 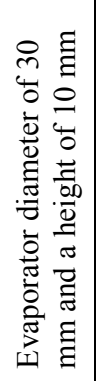 & 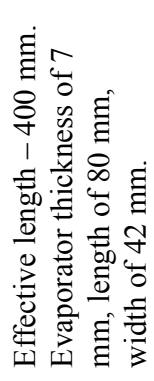 & 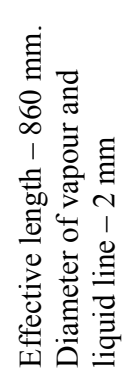 & 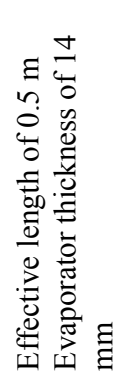 & 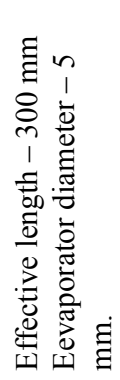 & 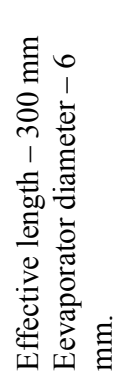 \\
\hline$\frac{\sqrt[5]{5}}{3}$ & $\begin{array}{l}\overline{\bar{\nu}} \\
\stackrel{\tilde{\omega}}{3}\end{array}$ & \begin{tabular}{l}
0 \\
\multirow{0}{0}{} \\
$\stackrel{0}{4}$
\end{tabular} & $\begin{array}{l}0 \\
\stackrel{0}{0} \\
\stackrel{0}{0} \\
\dot{0}\end{array}$ & , & $\begin{array}{l}\overline{\bar{v}} \\
\frac{\pi}{\pi} \\
3\end{array}$ & & 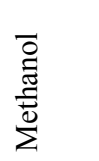 & $\begin{array}{l}\overline{\bar{v}} \\
\frac{\pi}{\pi} \\
3\end{array}$ & $\begin{array}{l}\overline{\bar{v}} \\
\vdots \\
\vdots\end{array}$ & 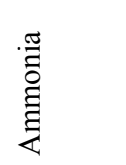 & $\begin{array}{l}. \frac{\pi}{7} \\
\stackrel{\Xi}{\Xi} \\
\text { 安 }\end{array}$ & $\begin{array}{l}. \frac{\pi}{Z} \\
\stackrel{\Xi}{\Xi} \\
\text { 紊 }\end{array}$ & 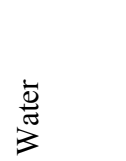 \\
\hline 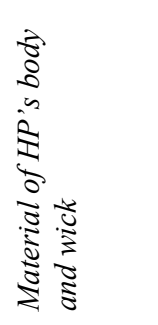 & 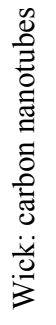 & 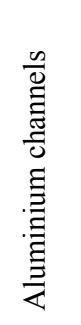 & & 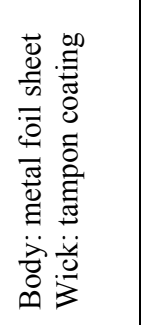 & 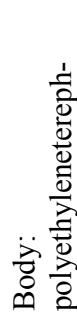 & 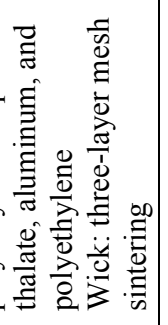 & 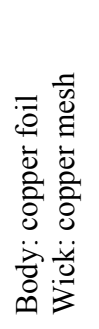 & 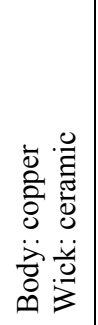 & 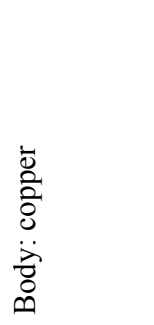 & 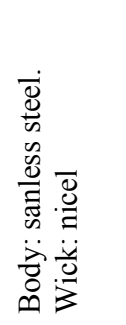 & 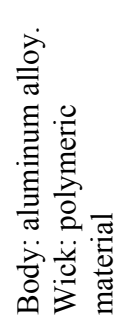 & 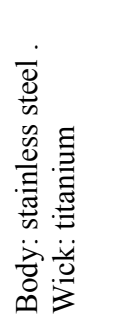 & 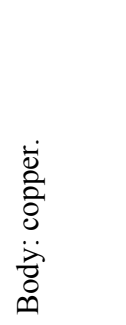 \\
\hline 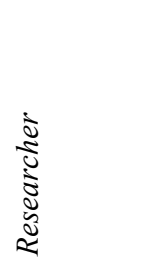 & 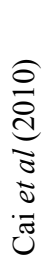 & 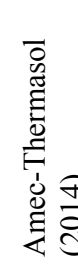 & & 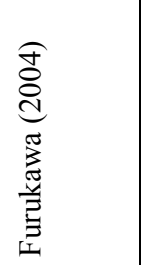 & 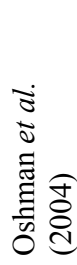 & & 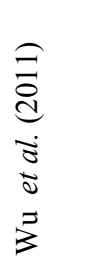 & 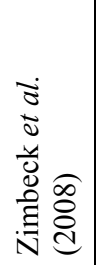 & 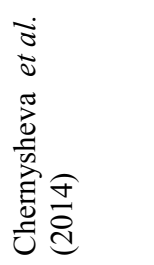 & 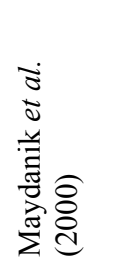 & 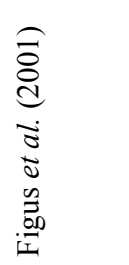 & 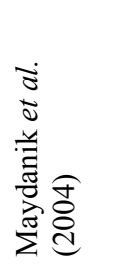 & \\
\hline 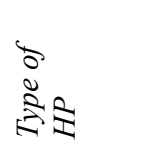 & \multicolumn{3}{|c|}{ 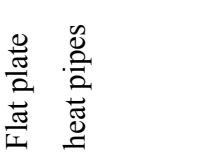 } & \multicolumn{4}{|l|}{ 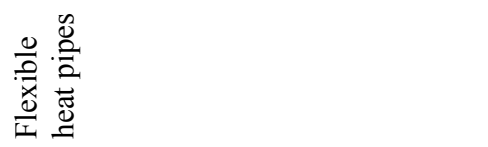 } & \multicolumn{6}{|l|}{ 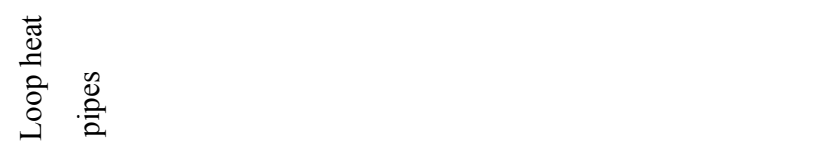 } \\
\hline
\end{tabular}


Table 2 (continuation)

\begin{tabular}{|c|c|c|c|c|c|c|c|c|c|c|c|c|c|c|c|}
\hline 胥 & : & m. & ô & & , & , & , & , & , & ' & , & $\begin{array}{c}3 \\
0 \\
\vdots \\
0 \\
0\end{array}$ & $\begin{array}{l}\overrightarrow{0} \\
0 \\
\vdots \\
0 \\
0 \\
0\end{array}$ & $\begin{array}{l}\overrightarrow{0} \\
\vdots \\
\vdots \\
0 \\
0\end{array}$ & $\begin{array}{c}0 \\
0 \\
0 \\
\vdots \\
\vdots \\
0 \\
0 \\
0\end{array}$ \\
\hline 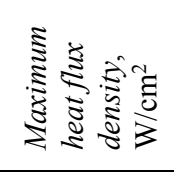 & . & . & . & , & , & , & , & . & , & ' & ' & , & , & & \\
\hline 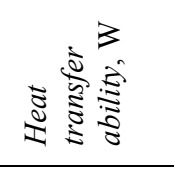 & 多 & , & $\begin{array}{l}\text { तิ } \\
1 \\
\stackrel{\text { ते }}{ }\end{array}$ & 尺े & $\overline{\vec{g}}$ & $\frac{n}{6}$ & ஓ̊+ & $\underset{\infty}{~}$ & $\tilde{\sigma}$ & $\stackrel{\infty}{\sim}$ & స్ & 8 & in & in & $\stackrel{8}{n}$ \\
\hline 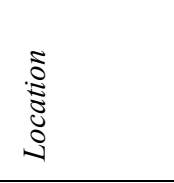 & . & , & , & $\begin{array}{l}: \\
\vdots \\
+\end{array}$ & 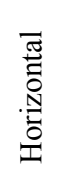 & $\begin{array}{l}\stackrel{2}{2} \\
\dot{+}\end{array}$ & 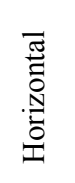 & $\begin{array}{l}\stackrel{2}{2} \\
\dot{+}\end{array}$ & 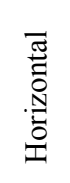 & $\begin{array}{l}\vdots \\
\vdots \\
+\end{array}$ & $\begin{array}{l}\stackrel{\circ}{2} \\
+\end{array}$ & 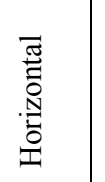 & 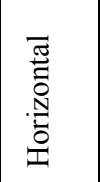 & 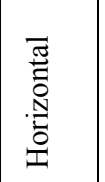 & 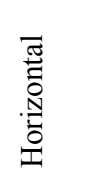 \\
\hline 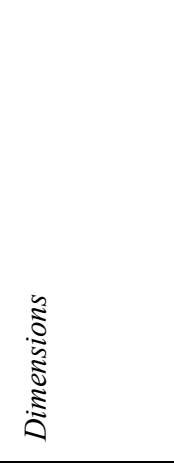 & 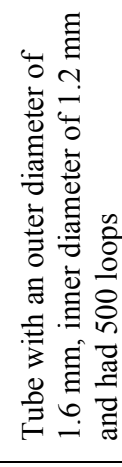 & 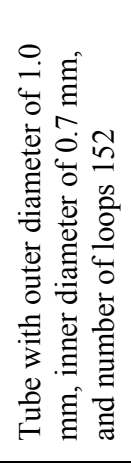 & 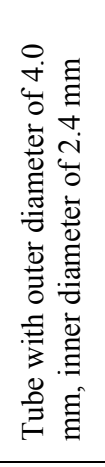 & 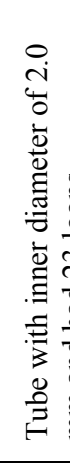 & & 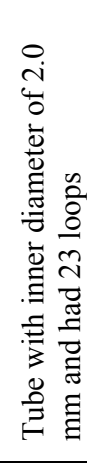 & & 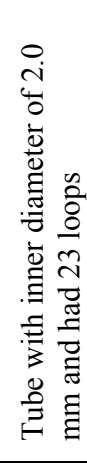 & & 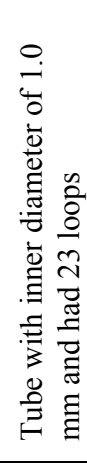 & 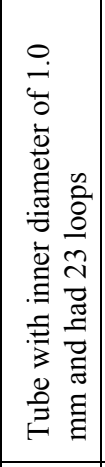 & 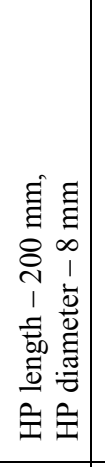 & 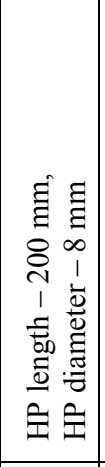 & 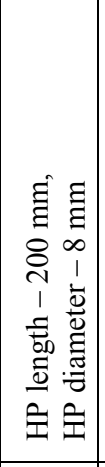 & 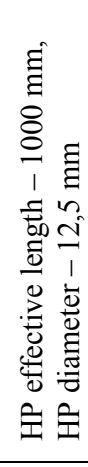 \\
\hline 离 & & $\frac{\overrightarrow{\widetilde{d}}}{\stackrel{\sim}{\sim}}$ & 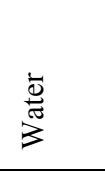 & $\frac{\pi}{\pi}$ & & $\begin{array}{l}\overline{\bar{o}} \\
\text { 葛 }\end{array}$ & & $\begin{array}{l}\frac{\tilde{g}}{\tilde{m}} \\
3\end{array}$ & & $\frac{\pi}{\pi}$ & $\begin{array}{l}\overline{\bar{o}} \\
\overline{\tilde{m}} \\
\text { 竎 }\end{array}$ & $\begin{array}{l}\frac{\breve{g}}{\tilde{J}} \\
⿱ 亠 䒑\end{array}$ & 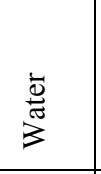 & $\frac{\breve{s}}{\stackrel{\tilde{m}}{3}}$ & 总 \\
\hline 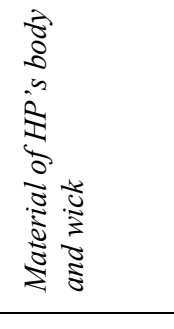 & 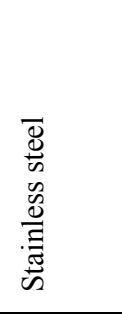 & 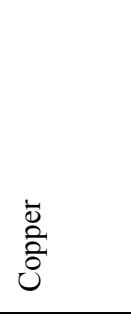 & 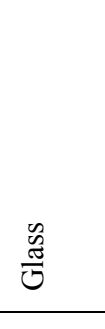 & $\begin{array}{l}\overline{\mathrm{o}} \\
\stackrel{0}{0} \\
0\end{array}$ & & & & & & & & 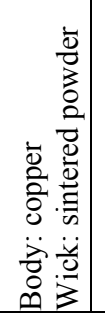 & 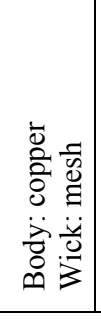 & 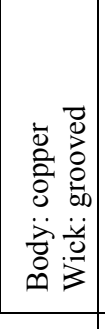 & 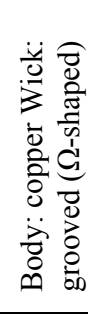 \\
\hline 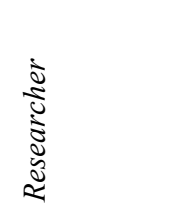 & 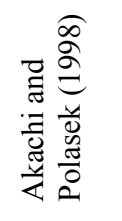 & & 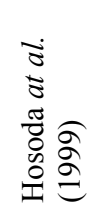 & 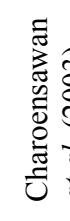 & & & & & & & & 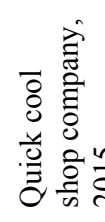 & & & 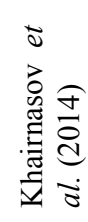 \\
\hline 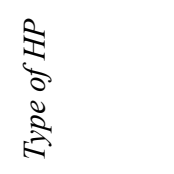 & 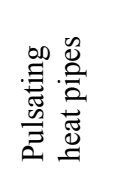 & & & & & & & & & & & 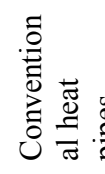 & & & \\
\hline
\end{tabular}


Furthermore, now water, alcohols, and acetone are mostly used in the LHP as coolants. It would be useful to generalize the data using experimental results obtained with one standard LHP design that covers different coolants (including Freons) for the temperature range from $-40^{\circ} \mathrm{C}$ up to $+100^{\circ} \mathrm{C}$.

\section{Pulsating heat pipes.}

Today a lot of researches are carried out in this area. Existing PHP samples are usually made of copper or stainless steel. Different liquids (acetone, alcohols, water, Freon) including nanofluids are used as coolants. However, there are still no general conclusions that allow to evaluate the joint effect of the PHP design factors on its performance. Present results, even obtained under the same conditions, often differ in the reports of different authors. This can be explained by complex processes in the PHP and above all their chaotic behavior complicating the description. All mentioned above determines the future path of the PHP study:

1. Description of heat-hydraulic processes within the PHP using statistical methods in order to create an analytical or numerical model of its functioning.

2. The need to study the complex influence of the PHP structural factors (number and lengths of the loops, pipe diameter, and type of coolant) on their performance in order to create methods for their design.

3. Improving the efficiency of the PHP by the use of nanofluids. In particular, both the nanofluids improvement and comprehensive study of their properties and PHP performance in order to select the optimal coolant.

\section{Conventional heat pipes.}

These heat pipes are the most studied at present day. However, there is a number of promising directions for research in this area concerned with the growth of the HP efficiency:

1. Development and research of double-porous capillary structures with variable porosity, which allows on the one hand to intensify the heat transfer process in the HP and on the other hand to reduce their flow resistance. Such studies may include both homogeneous wick (e.g. powder) and combined ones (e.g. powder - metal-fiber).

2. Research of the grooved HP that operate in the thermosyphon mode and development of the optimized grooved wick for this mode. Such structures in comparison with smooth-wall thermosyphon can increase the transferred heat flows more than 1.5 times and reduce the thermal resistance more than 2 times. Furthermore, intensification of heat transfer processes in the grooved wick, for example by sputtering or other deposition of particles on their surfaces is also promising.

\section{Heat pipes.}

In conclusion, it should be noted that the most promising and important tasks in the development of the HP for electronics thermal control systems are:

1. HP miniaturization at simultaneous maintaining or providing its highest possible productivity. The study of the heat-hydraulic processes in confined spaces can open up new ways of increasing the efficiency of micro and miniature HP.

2. Search for non-metallic materials for the body and wick production. This issue today is the most interesting and most discussed. The search for new non-metallic materials (e.g. polymer) able to provide long HP's life time may open new borders of its use.

3. Search for new coolants. In many ways the performance of the HP depends on the properties of the coolant. And the solution of this problem makes it possible to improve the performance of the heat pipes having similar designs. In particular creation an inhibitor for system "aluminium - water" could open way for more broad aluminium heat pipes application.

\section{CONCLUSIONS}

The article describes various applications of the heat pipes in electronics thermal control systems. Today, using of the HP in the electronics cooling systems becomes necessary. Different types of the HP are used as elements of electronics thermal control systems, they are: micro- and miniature HP, vapor chambers, flat plate HP, flexible HP, round HP with different types of wick, loop HP, and pulsating HP. Each type of the HP has its advantages and disadvantages, which determine their application in this or that electronics cooling system. However, it should be taken into account that HP add some extra thermal resistance. When designing a circuit it is necessary to provide a solution that compensates this thermal resistance, for example by increasing the developed surface and efficiency of the heat sink. Furthermore, it is desirable to design the assembly so that the HP will operate in thermosyphon mode, while ensuring high heat transfer capacity and low values of thermal resistance. In other cases it is necessary to take into account the ability of the HP work against gravity as well as its efficiency. Only in this case the HP will ensure effectiveness of the thermal control system. This can be achieved by comprehensive approach to the designing of both the electronic products and the electronics thermal control system based on the HP.

\section{REFERENCES}

Akachi, H., Polasek, F., 1998, "Thermal control of IGBT Modules in Traction Drives by Pulsating Heat Pipes," Preprint $10^{\text {th }}$ Int. Heat Pipes Conf., Vol. 3, Stuttgart, Germany, $8-12$.

AmecThermasol, 2014, "MHP Series,” Booklet. http://www.amecthermasol.co.uk/AmecThermasolPDF/MHP Series.pdf

Badran, B., Gerner, F., Ramada, P., Henderson, T., Baker, K., 1997, "Experimental Results for Low-Temperature Silicon Micromashined Micro Heat Pipe Arrays Using Water and Methanol as Working Fluids," Experimental Heat Transfer, 10(4), 253 - 272. http://dx.doi.org/10.1080/08916159708946547

Bliss F.E., Clark E.G. and Stein B., 1970, "Construction and Test of a Flexible Heat Pipe," Proceedings of ASME Space Systems and Thermal Technologies for the 70's, 1-7.

Cai, Q., Chen, C.L., 2010, "Design and Test of Carbon Nanotube Biwick Structure for High-Heat Flux Phase Change Heat Transfer," J. Heat Transfer, 132, 052403-1-8.

http://dx.doi.org/10.1115/1.4000469

Charoensawan, P., 2003, "Heat Transfer Characteristics of Closed Loop Oscillating Heat Pipes," Ph.D. Thesis, Chiang Mai University, Chiang Mai, Thailand.

Chernysheva, M.A., Yushakova, S.I., Maydanik, Y.F., 2014, "Copper Water Loop Heat Pipes for Energy-Efficient Cooling Systems of Supercomputers," Energy, 69, 534 - 542.

http://dx.doi.org/10.1016/j.energy.2014.03.048

Ektummakij, P., Kumthonkittikun, V., Kuriyama, H., Mashiko, K., Mochizuki, M., Saito, Y., Nguyen, T., 2004, "New Composite Wick Heat Pipe for Cooling Personal Computers," Preprints of the $13^{\text {th }}$ International Heat Pipe Conference, Shanghai, China, 263 - 268.

Figus, C., Pullet, C., Supper, W., 2001, "Development of Miniaturized Fluid Loops in Astrium," Proceedings of Int. Two-Phase Thermal Control Technology Workshop, El Segundo, CA.

Furukawa, 2004, "Ultra-Thin Sheet-Shaped Heat Pipe 'Pera-flex," Furukawa Rev. 2564-6.

https://www.furukawa.co.jp/review/fr025/fr25 14.pdf 
Furukawa, 2014, "A Reliable Advanced Cooling Technology Meets High Density Mounting for Electronic Application," Booklet.

Hosoda, M., Nishio, S. and Shirakashi, R., 1999, "Study of Meandering Close-Loop Heat-Transport Device (Vapor-plug Propagation Phenomena)," JSME Int. Journal, Series B, 42(4), 737-743.

Huang, B.J., Wang, C.H., Lin, T.T., Huang, H.H., Yeh, Y.Y., 2004, "Development of a Low-Cost LHP for Commercial Application," Proceedings of the 13th International Heat Pipe Conference, Shanghai, China, 211 - 215.

Khairnasov, S.M., Rassamakin, B.M., Rassamakin, A.B., 2014, "The use of Aluminum Heat Pipes in the Cooling Systems of Electronic Equipment," Proceedings of XV International Scientific-Practical Conference "Modern Information and Electronic Technologies," Odessa, Ukraine, 8-11.

Khandekar, S., 2004, "Thermo-Hydrodynamics of Closed Loop Pulsating Heat Pipes," Ph.D. Thesis, University of Stuttgart, Germany.

Koito, Y., Imura, H., Mochizuki, M., Saito, Y., and Torii, S., 2006, "Fundamental Experiments and Numerical Analyses on Heat Transfer Characteristics of a Vapor Chamber (Effect of Heat Source Size)," JSME International Journal, Series B, 49(4), 1233-1240.

http://dx.doi.org/10.1299/jsmeb.49.1233

Kravets, V.Yu., Nikolaenko, Yu.E., Nekrashevich, Ya.V. "Experimental Studies of Heat-Transfer Characteristics of Miniaturized Heat Pipes," Heat Transfer Research, 38(6), 553-563.

http://dx.doi.org/10.1615/HeatTransRes.v38.i6.70

Kravets, V.Yu., Buhtiyarov, Yu.V., Shturma, I.Yu., Palamarchuk, A.Ya, 2013, "Cooling Device for Electronic Components," Patent of the Russian Federation for the invention №2474888, Bul. № 4.

Lallemand, M., Lefevre, F., 2004, "Micro/Mini Heat Pipes for the Cooling of Electronic Devices," Preprints of the 13th International Heat Pipe Conference, Shanghai, China, 12 - 23.

Lefevre, F. and Lallemand, M., 2006, "Coupled Thermal and Hydrodynamic Models of Flat Micro Heat Pipes for the Cooling of Multiple Electronic Components," International Journal of Heat and Mass Transfer, 49, 1375-1383.

http://dx.doi.org/10.1016/j.ijheatmasstransfer.2005.10.001

Lin, J. C., Wu, J. C., Yen, C. T., and Yang, C. Y., 2004, "Fabrication and Performance Analysis of Metallic Micro Heat Spreader for CPU", Proceedings of 13th International Heat Pipe Conference, Shanghai, China, 21-25.

Miao, J., Li, S., Yang, H., Fu, W., Jiang, H. and Yu, L., 2007, "Development of Mini-heat Pipes for Payload Thermal Control of Satellites," Preprints of the $14^{\text {th }}$ International Heat Pipes Conference, Florianopolis, Brazil, 1-5.

Wang, J. C., 2010, "Development of Vapour Chamber-Based VGA Thermal Module", International Journal of Numerical Methods for Heat \& Fluid Flow, 20(4), 416-428.

http://dx.doi.org/10.1108/09615531011035811

Maydanik, Y., Vershinin, S., Korukov, M., and Ochterbeck, J., 2005, "Miniature Loop Heat Pipes - A Promising Means for Cooling Electronics", IEEE Transactions on Components and Packaging Technology, 28(2), 290-296.

http://dx.doi.org/10.1109/TCAPT.2005.848487
Maydanik, Yu.F., Vershinin, S.V., Korukov, M.A., Ochterbeck, J.M., 2004, "Miniature Loop Heat Pipes - a Promising Means for Cooling Electronics," Proceedings of 9th Intersociety Conference on Thermal and Thermomechanical Phenomena in Electronic Systems, Las Vegas, NV.

http://dx.doi.org/10.1109/ITHERM.2004.1318253

Maydanik, Yu.F., Vershinin, S.V., Chernyshova, M.A., 2000, "Development and Tests of Miniature Loop Heat Pipes with a Flat Evaporator," 2000-01-2491. Proceedings of 30th Int. Conference on Environmental Systems and 7th European Symposium on Space Environmental Control Systems, Toulouse, France. http://dx.doi.org/10.4271/2000-01-2491

Naphon, P., Thongkum, D. and Assadamongkol, P., 2009, "Heat Pipe Efficiency Enhancement with Refrigerant-Nanoparticles Mixtures," Journal of Energy Conversion and Management, 50(3), 772-776. http://dx.doi.org/10.1016/j.enconman.2008.09.045

Niloofar Mohammadi, Maziar Mohammadi, Mohammad Behshad Shafii, 2012, "A Review of Nanofluidic Pulsating Heat Pipes: Suitable Choices for Thermal Management of Electronics," Frontiers in Heat Pipes, 3, 033001.

http://dx.doi.org/10.5098/fhp.v3.3.3001

Oshman, C., Shi, B., Li C., Yang, R.G., Lee, Y.C., Peterson, G.P. and Bright, V.M., 2004, "The Development of Polymer-Based Flat Heat Pipes," J. Microelectromech. Syst., 20, 410-417. http://dx.doi.org/10.1109/JMEMS.2011.2107885

Rassamakin, B.M., Nikolaenko, Yu.E., Khairnasov, S.M., 2009, "Research of the Tilt Angles Influence on Thermal Characteristics of the Water Cooling System for the Instrument Cabinet Based on Heat Pipes," Proceedings of XV International Scientific-Practical Conference "Modern Information and Electronic Technologies", Odessa, Ukraine, $73-75$.

Reay, D.A., Kew, P.A., 2006, "Heat Pipes. Theory, Design and Application (5 ed.)," Butterworth-Heinemann, 374.

Gnilichenko, V.I., Smirnov, G.F., Tkachenko, V.B., 1999, "Heat Pipes in the Electronics Thermal Control Systems," Technology and Designing in the Electronic Equipment, 4, 15 - 19.

Singh, R., Mochizuki M., Mashiko K., Nguyen, T., 2011, "Heat Pipe Based Cold Energy Storage Systems for Datacenter Energy Conservation," Energy, 36, 2802 - 2811.

http://dx.doi.org/10.1016/j.energy.2011.02.021

Singh, R., Akbarzadeh, A., Dixon, C., Mochizuki, M., Riehl, R.R., 2007, "Miniature Loop Heat Pipe With flat Evaporator for Cooling Computer CPU," IEEE Trans Comp Pack Technol., 30(1), 42 - 49. http://dx.doi.org/10.1109/TCAPT.2007.892066

Sukhvinder, S. Kang, 2012, "Advanced Cooling for Power Electronics," Preprints of International Conference on Integrated Power Electronics Systems, CIPS, Nuremberg, Germany, $1-8$.

Vasiliev, L.L., Antukh, A.A., Maziuk, V.V., Kulakov, A.G., Rabetsky M.I., Vasiliev Jr L.L.., Oh Se Min, 2002, "Miniature Heat Pipes Experimental Analysis and Software Development," Proceedings of the $12^{\text {th }}$ International Heat Pipe Conference, Moscow, 329 - 335.

Vasiliev, L.L., 2005, "Micro and Miniature Heat Pipes - Electronic Components Cooler," Proceedings of the VI Minsk International 
Seminar "Heat Pipes, Heat Pumps, Refrigerators", Minsk, Belarus, 74 $-76$.

Wang, J. C., 2009, "Superposition Method to Investigate the Thermal Performance of Heat Sink with Embedded Heat Pipes," International Communications in Heat and Mass Transfer, 36(7), 686-692. http://dx.doi.org/10.1016/j.icheatmasstransfer.2009.04.008

Wang, J. C., Wang, R. T., Chang, C. C., and Huang, C. L., 2010, "Program for Rapid Computation of the Thermal Performance of a Heat Sink with Embedded Heat Pipes", Journal of the Chinese Society of Mechanical Engineers, 31 (1), 21-28.

Wang, R.T., Wang, J.C., and Chang, T.L., 2011, "Experimental Analysis for Thermal Performance of a Vapour Chamber Applied to High-performance Servers," Journal of Marine Science and Technology, 19(4), 353-360.

Wang, S., Lin, Z., Zhang, W., and Chen, J., 2009, "Experimental Study on Pulsating Heat Pipe with Functional Thermal Fluids," International Journal of Heat and Mass Transfer, 52(21-22), 5276 $-5279$.

http://dx.doi.org/10.1016/j.ijheatmasstransfer.2009.04.033

Wang, S., Lin, Z., Zhang, W., Chen, J., and Tang, Y., 2009, "Heat Transport Characteristics of an Oscillating Heat Pipe with $\mathrm{Al}_{2} \mathrm{O}_{3}$ Nanofluid," Preprints of 2nd Micro/Nanoscale Heat \& Mass Transfer International Conference, Shanghai, China.

Wang, X.D., Zou, L.L., Liu, J.G., Luo, Yi., Liu, G. and Yu, B.K., 2014, "Experimental Investigation of Copper-grooved Micro Heat Pipes (MHPs)," Journal of Solid State Lighting, 1(14), 1 - 8.

http://dx.doi.org/10.1186/s40539-014-0014-5
Wei, J., 2006, "Challenges in Cooling Design of CPU Packages for High-Performance Servers," Heat Transfer Engineering, 29(2), 178187.

Wei. X., Sikka, K., 2006, "Modeling of Vapor Chamber as Heat Spreading Devices," Proceedings of the 10th Intersociety Conference on Thermal and Thermomechanical Phenomena in Electronics Systems, San Diego, California.

Wilson, C., Borgmeyer, B., Winholtz, R.A., Ma, H.B., Jacobson, D.L., and Hussey, D.S., 2011, "Thermal and Visual Observation of Water and Acetone Oscillating Heat Pipes," Journal of Heat Transfer, 133(6), 061502 .

http://dx.doi.org/10.1115/1.4003546

Wu G.W., Shih W.P. and Chen S.L., 2011, "Lamination and Characterization of a PET Flexible Micro Heat Pipe," Preprints of the 10th Int. Heat Pipe Symp., Taipei, Taiwan, pp. 1-6.

Yu C.S., Wei W.C., Kang S.W., 2007, "Investigation of Micro Porosity Sintered wick in Vapor Chamber for Fan Less Design," Proceedings of the Conference Thermic 2007, Budapest, Hungary, 1 - 4. http://dx.doi.org/10.1109/THERMINIC.2007.4451753

Zimbeck, W., Slavik, G., Cennato, J., Kang, S., Yun, J., Kroliczek, E., 2008, "Loop Heat Pipe Technology For Cooling Computer Servers," Proceedings of the 11th IEEE conference on thermal thermomechanical phenomena in electronic systems, Orlando, Fl, 19 - 25. http://dx.doi.org/10.1109/ITHERM.2008.4544248

Zhang, Y., and Faghri, A., 2008, "Advances and Unsolved Issues in Pulsating Heat Pipes," Journal of Heat Transfer Engineering, 29(1), 20-44.

http://dx.doi.org/10.1080/01457630701677114 